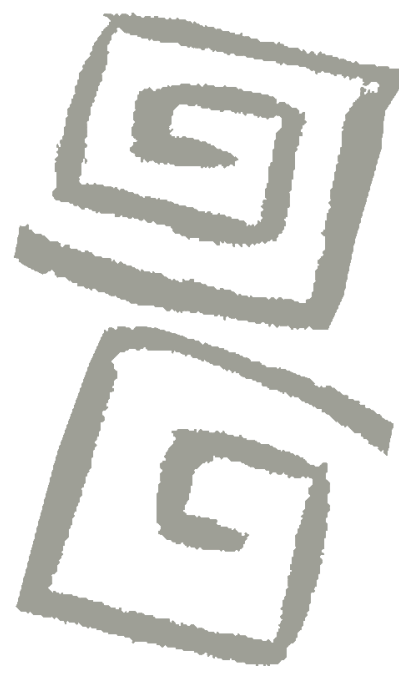

\title{
Distribución geográfica de fluoruros en el agua de red de abastecimiento público en la provincia de Tucumán, Argentina
}

\author{
Geographical distribution of fluoride in the public \\ water supply in the province of Tucumán, Argentina
}

Raúl Alberto Durán ${ }^{1}$, Estela Liliana Durán², Graciela de Jesús Ojeda ${ }^{3}$, Walter
Alfredo Castellanos ${ }^{4}$

'Bioquímico, Magíster en Gestión Ambiental. Analista, Laboratorio de Control de Agua Potable, Departamento de Saneamiento Básico, Dirección General de Salud Ambiental, Sistema Provincial de Salud, Tucumán, Argentina. $\square$ (iD)

${ }^{2}$ Bioquímica. Doctora en Ciencias Biológicas. Jefa, Laboratorio de Control de Agua Potable, Departamento de Saneamiento Básico, Dirección General de Salud Ambiental, Sistema Provincial de Salud, Tucumán, Argentina. $\bowtie$ (iD

${ }^{3}$ Bioquímica. Jefa, Departamento de Saneamiento Básico, Dirección General de Salud Ambiental, Sistema Provincial de Salud, Tucumán, Argentina. $\bowtie$ (iD)

${ }^{4}$ Ingeniero Químico, Ingeniero Agrónomo. Director, Dirección General de Salud Ambiental, Sistema Provincial de Salud, Tucumán, Argentina. $\triangle$ (iD)
RESUMEN Con el objetivo de estudiar la distribución geográfica del contenido de fluoruros en el agua de abastecimiento público de la provincia de Tucumán, Argentina, se recolectaron 1.210 muestras en 190 localidades de los 17 departamentos de la provincia durante el periodo 2008-2012. Las determinaciones analíticas de fluoruros se realizaron por el método SPANDS y, para el procesamiento de la información, se utilizó el programa QGis 2.16. Los requerimientos del contenido de fluoruros en el agua se identificaron de acuerdo al Código Alimentario Argentino. El 94\% de la población estudiada consumía agua con concentraciones de fluoruros inferiores a los límites recomendados, un $5 \%$ estaba expuesta a concentraciones de fluoruros superiores al límite máximo requerido y el $1 \%$ consumía agua en concentraciones óptimas de fluoruros. En los mapas se visualiza una distribución geográfica heterogénea de fluoruros, diferenciada por áreas con déficit, exceso y valores recomendados de fluoruros que, en algunos departamentos, permite observar una relación inversa entre la red hidrológica y el parámetro de estudio. Para la Capital el valor promedio encontrado fue de 0,32 mg/l, con una distribución geográfica homogénea. La información obtenida es indispensable para el adecuado manejo del flúor y la mejora de la salud pública a través de políticas sanitarias.

PALABRAS CLAVES Agua Potable; Fluoruros; Caries Dental; Prevención de Enfermedades; Argentina.

ABSTRACT This work studied the geographical distribution of fluoride content in the public water supply in the province of Tucumán, Argentina. A total of 1,210 samples were collected in 190 localities of the 17 departments of the province during the 20082012 period. The analytical determination was performed using the SPADNS method and QGis 2.16 was used for processing the information. The fluoride content requirements in the studied localities were determined according to the Argentine Food Code. The results showed that $94 \%$ of population studied consumed water with fluoride concentrations below the recommended limits, $5 \%$ were exposed to fluoride concentrations above the required maximum limit and $1 \%$ consumed water at optimal fluoride concentrations. The maps showed a heterogeneous geographical distribution of fluorides, in which areas with deficit, excess and recommended values of fluorides can be differentiated; in some departments an inverse relationship between the density of the hydrological network and fluoride concentration can be observed. In the capital of the province, the average value found was $0.32 \mathrm{mg} / \mathrm{l}$, presenting a homogeneous geographical distribution. The information obtained is indispensable for the proper management of fluoride, so as to improve public health through policy.

KEY WORDS Drinking Water; Fluorides; Dental Caries; Disease Prevention; Argentina. 


\section{INTRODUCCIÓN}

La caries dental constituye uno de los principales problemas de salud bucal en el mundo. Los estudios realizados por la Organización Mundial de la Salud (OMS) ${ }^{(1)}$ reportan una prevalencia de hasta el $98 \%$ en la población general. En los países en desarrollo, la caries dental es un problema de salud pública ${ }^{(2)} y$, en Argentina, la tendencia es coincidente y existe una elevada prevalencia de caries en la población de niños y adolescentes ${ }^{(3)}$.

La caries dental se define como un proceso o enfermedad dinámica crónica, que ocurre en la estructura dentaria en contacto con los depósitos microbianos, y por el desequilibrio entre la sustancia dental y el fluido de placa circundante, lo que da como resultado una pérdida de mineral de la superficie dental, cuyo signo es la destrucción localizada de tejidos duros ${ }^{(4)}$.

Los factores más importantes asociados a la presencia de caries dental son la higiene bucal, la susceptibilidad individual, la exposición a fluoruros, los hábitos alimenticios, la accesibilidad a servicios estomatológicos, y las condiciones socioeconómicas ${ }^{(5)}$.

Con relación a la exposición a fluoruros, estos pueden ser ingeridos con los alimentos, el agua, la leche, o la sal y actúan en la placa bacteriana y en la remineralización del esmalte, a través de la saliva ${ }^{(6)}$. El fluoruro disponible en saliva y placa bacteriana es el principal responsable del efecto preventivo en las caries $^{(7)}$.

El exceso de flúor consumido por distintas vías podría producir riesgos, como la fluorosis dental y fluorosis ósea. Cuando el agua contiene más de 3-6 mg/l de fluoruros se ha observado casos de fluorosis esquelética ${ }^{(8)}$. En 1929, McKay $^{(9)}$ postuló una asociación entre la fluorosis y el esmalte dental moteado y una relación inversa entre la frecuencia de caries y el contenido de fluoruros en el agua. En una revisión sistemática sobre los efectos adversos de la fluoración del agua desde el 2002 al $2012^{(10)}$ se encontró que, con excepción de la fluorosis dental, no hay asociación entre la fluoración del agua con fracturas óseas, cáncer u otro efecto adverso.

El estudio geográfico del contenido de fluoruros en aguas de consumo humano permite visualizar la información e interpretarla, analizando patrones, tendencias y relaciones a fin de facilitar la resolución de problemas complejos de planificación y gestión de territorios ${ }^{(11)}$. En este sentido, el análisis de la distribución espacial del contenido de fluoruros en el agua de consumo en la provincia de Tucumán permite diferenciar áreas de concentración semejantes, teniendo en cuenta los requerimientos de la legislación vigente, y relacionarlas, en general, con la red hidrológica y el relieve.

Tekle-Haimanot et al. ${ }^{(12)}$ relevaron la distribución geográfica de fluoruros en aguas superficiales y profundas en Etiopía, y encontraron una variación espacial en la distribución de fluoruros, aun en pequeñas áreas. Según lo informado por Cuellar Luna y García Melián ${ }^{(13)}$, la mayor proporción de fluoruros que llega a los recursos hídricos procede de la lixiviación de rocas y suelos, la cual está en estrecha relación con las características geológicas de cada terreno.

Existe una fuerte evidencia de que la fluoración de las agua es efectiva para controlar las caries dental dentro de las comunidades urbanas $^{(14)}$, del mismo modo Muñoz Millán ${ }^{(15)}$ reportan la fluoración de la leche en comunidades rurales de Chile. La fluoración del agua de consumo, como método preventivo, es eficaz y de amplitud colectiva. Se reporta en algunas ciudades brasileñas una reducción en la prevalencia de caries dental, desde el $44 \%$ al $79 \%{ }^{(16)}$. Armfield ${ }^{(17)}$ documentó que los niños que viven en Australia en áreas con concentraciones menores a $0,3 \mathrm{mg} / \mathrm{l}$ de fluoruro en el agua tienen mayor experiencias y prevalencia de caries que sus homólogos de la misma edad que residen en áreas con concentraciones óptimas de fluoruro en el agua $(>0,7 \mathrm{mg} / \mathrm{l})$.

Estudios similares realizados en Isparta, Turquía, permitieron optimizar la concentración de fluoruros en el agua, luego de caracterizar las fuentes, reduciendo los riesgos de fluorosis ${ }^{(18)}$. 
Al considerar la relación entre la distribución de fluoruros y las características topográficas de la zona de estudio Cuellar et al. ${ }^{(13)}$, en la Habana, resaltan la importancia de la intervención positiva, por fluoración de las aguas, reduciendo los índices de caries dentales.

En Argentina, varios autores ${ }^{(3,19,20)}$ estudiaron el contenido de fluoruros en el agua de consumo. En el año 1975, se sancionó en el país la Ley $21172 / 75$, que dispone la fluoración o defluoración del agua de consumo hasta alcanzar el nivel óptimo del ión flúor. Desde entonces, las provincias de Misiones, Río Negro, Tucumán y Santa Fe han adherido a la propuesta de la mencionada ley y han implementado planes de fluoración de las aguas de consumo. Sin embargo, en la actualidad, no se están ejecutando dichos planes de fluoración en la provincia de Tucumán.

En la provincia de Tucumán, los estudios sobre el contenido de fluoruros en el agua de abastecimiento público se remontan a la década de $1980^{(21)}$. En 147 muestras de agua de consumo se encontraron concentraciones de fluoruros en el agua de bebida con valores medios de $0,43 \mathrm{mg} / \mathrm{l}$ y $0,24 \mathrm{mg} / \mathrm{l}$ para la provincia y en San Miguel de Tucumán, respectivamente, tomando como referencia los límites recomendados de 0,7 mg/l y 1,0 mg/l, por las Normas de Agua Potable del Servicio de Salud Pública de EE.UU., para un valor de temperatura del aire máximas promedio anual de $24,6{ }^{\circ} \mathrm{C}$ de la provincia de Tucumán ${ }^{(22)}$.

La OMS toma el valor límite de fluoruros en el agua de bebida de $1,50 \mathrm{mg} / \mathrm{I}^{(23)}$, y destaca la necesidad de tener en cuenta las condiciones climáticas, el volumen de agua ingerido y la ingesta de fluoruros procedentes de otras fuentes. En ese sentido, el Código Alimentario Argentino (CAA) ${ }^{(24)}$ establece los límites mínimos y máximos en el contenido de fluoruros, en función de la temperatura máxima promedio de la zona. El objetivo del presente estudio fue obtener información sobre el contenido de fluoruros en el agua de consumo humano en la provincia de Tucumán y evaluar su distribución geográfica, a los fines de tomar las medidas preventivas en beneficio de la salud de la población.

\section{MATERIALES Y MÉTODOS}

La provincia de Tucumán está ubicada en el noroeste de Argentina, entre los meridianos $26^{\circ}$ y $28^{\circ}$ de latitud sur y los paralelos $64^{\circ}$ y $68^{\circ}$ de longitud oeste, tiene una superficie de $22.524 \mathrm{~km}^{2}$, su población alcanza a 1.448.400 habitantes ${ }^{(25)}$ y constituye la provincia más densamente poblada del país $\left(64,3 \mathrm{hab} / \mathrm{km}^{2}\right)$. Presenta zonas con amplia variación de temperaturas máximas medias anuales que oscilan, entre $\operatorname{los} 19^{\circ} \mathrm{C}$ y los $28^{\circ} \mathrm{C}$. El clima predominante es subtropical, con estación seca en invierno. La capital de la provincia, San Miguel de Tucumán, concentra el $37,9 \%$ de la población.

Durante el periodo 2008-2012, se recolectaron 1.210 muestras de aguas de consumo distribuida por red, de 190 localidades de los 17 departamentos que componen la provincia de Tucumán. Los sitios de muestreos fueron georeferenciados mediante un equipo Garmin eTrex Legend HCx y los datos fueron procesados mediante los programas MapSource, OpenOffice 3.4.1, ArcView Gis 3.2, Adobe Photoshop CS4, y QGis 2.16. Para la elaboración de los mapas de calor se utilizó la capa vectorial de puntos de concentración de fluoruros de cada localidad estudiada, se generó un raster de salida con un ancho de banda (radio de búsqueda) de $5 \mathrm{~mm}$, y se ponderó la concentración de fluoruros de cada punto georeferenciado. Se utilizó una relación de decadencia igual a cero.

Los sitios de muestreos fueron seleccionados de acuerdo a la distribución demográfica de la población, para lo cual se seleccionaron localidades con más de 200 habitantes, coincidente con la distribución de los centros de atención de salud de la provincia. En cada localidad se tomaron muestras de un centro de salud, de un establecimiento educativo y de un usuario. En San Miguel de Tucumán, se realizó un muestreo por áreas, considerando los antecedentes de la concentración de fluoruros en el agua y la interconexión de las fuentes de suministro en la red de distribución. Este esquema de muestreo se realizó en el periodo 2008-2012 durante el 
cual se estudió la distribución del contenido de fluoruros en el agua de red, de acuerdo a las recomendaciones de la $\mathrm{OMS}^{(23)}$.

Las muestras recolectadas se trasladaron al laboratorio de análisis, cumpliendo con los métodos estándares de conservación y cadena de custodia. Las determinaciones analíticas de fluoruros se realizaron por el método colorimétrico estandarizado SPANDS ${ }^{(23,26)}$-sal trisódica del ácido 1,8-dihidroxi-2-(4-sulfofenilazo) naftalen-3,6-disulfónico- basado, en la reacción química entre el ión fluoruro y una laca coloreada de zirconio, que provoca una disminución del color, el cual es medido espectrofotométricamente a $570 \mathrm{~nm}$ de longitud de onda con un espectrofotómetro marca Metrolab 1600 plus. Para los controles de calidad, se usaron soluciones patrones comerciales de fluoruros.

Los registros de estaciones meteorológicas, la información de mapas de isotermas ${ }^{(27,28,29)}$ y los datos suministrados por el Instituto Geográfico Nacional ${ }^{(30)}$ y el Servicio Meteorológico Nacional fueron empleados para diferenciar las áreas geográficas según las temperaturas máximas medias anuales del aire en las zonas de estudio. El déficit y exceso de fluoruros fue valorado según los límites establecidos por el Código Alimentario Argentino $^{(24)}$, para las temperaturas máximas medias anuales de aire, de las zonas de estudio.

\section{RESULTADOS}

En la Figura 1 se representa la distribución geográfica de los fluoruros en agua de consumo, y en la Tabla 1 se presentan los valores de concentración de fluoruros, los rangos de temperaturas y los límites de fluoruros según los requerimientos del Código Alimentario Argentino para las localidades estudiadas. La Figura 2 muestra los sitios de muestreos y las isotermas de temperaturas máximas medias anuales del aire, acorde a rangos de temperaturas máximas medias anuales y a los límites recomendados por el Código Alimentario Argentino para el contenido de fluoruros en el agua de bebida (Tabla 2).

La zona Este, que incluye el Gran San Miguel de Tucumán tiene una población de

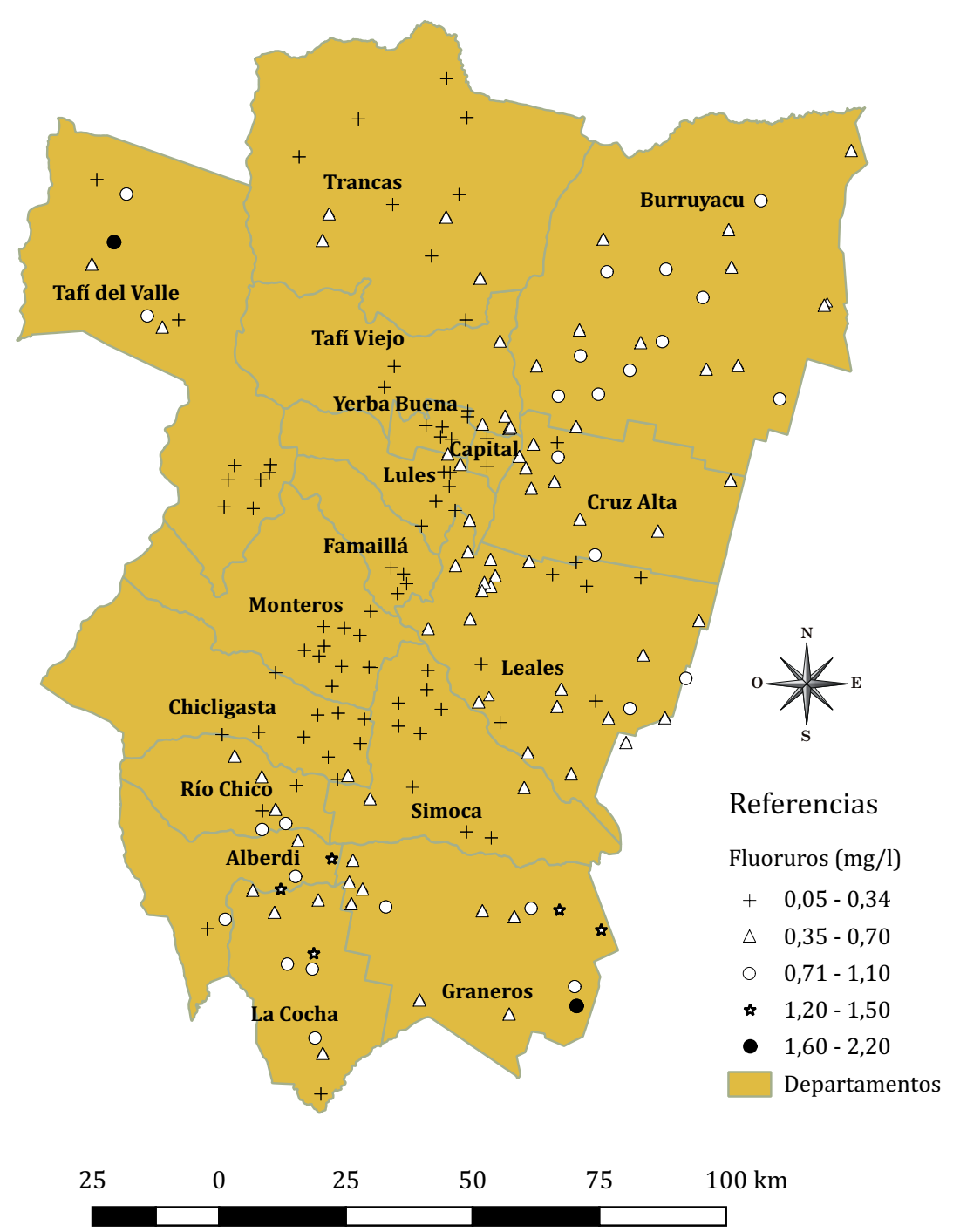

Figura 1. Distribución de la concentración de fluoruros en el agua de red. Provincia de Tucumán, Argentina, 2008-2012.

Fuente: Elaboración propia con base en geodato del Instituto Geográfico Nacional ${ }^{(30)}$ 
Tabla 1. Concentraciones de fluoruros distribuidas por localidades, rango de temperatura máxima media anual y límites mínimo y máximo de fluoruros, según los requerimientos del Código Alimentario Argentino. Provincia de Tucumán, Argentina, 2008-2012.

\begin{tabular}{|c|c|c|c|c|c|}
\hline \multirow[t]{2}{*}{ Departamento } & \multirow[t]{2}{*}{ Localidad } & \multirow{2}{*}{$\begin{array}{l}\text { Concentración de } \\
\text { fluoruros } \\
(\mathrm{mg} / \mathrm{l})\end{array}$} & \multirow{2}{*}{$\begin{array}{c}\text { Rango de } \\
\text { temperaturas } \\
\left({ }^{\circ} \mathrm{C}\right)\end{array}$} & \multicolumn{2}{|c|}{ Límites de fluoruros } \\
\hline & & & & $\begin{array}{c}\text { Mínimo } \\
\text { (mg/l) }\end{array}$ & $\begin{array}{c}\text { Máximo } \\
\text { (mg/l) }\end{array}$ \\
\hline \multirow{6}{*}{ Alberdi } & Villa Belgrano & 0,6 & $26-28$ & 0,6 & 0,8 \\
\hline & Talamuyo & 1,4 & $26-28$ & 0,6 & 0,8 \\
\hline & Escaba de Abajo & 0,2 & $22-26$ & 0,7 & 1,0 \\
\hline & Villa de Escaba & 1,0 & $22-26$ & 0,7 & 1,0 \\
\hline & Marapa & 1,2 & $22-26$ & 0,7 & 1,0 \\
\hline & Juan B. Alberdi & 0,8 & $22-26$ & 0,7 & 1,0 \\
\hline \multirow{22}{*}{ Burruyacú } & La Cruz & 0,8 & $26-28$ & 0,6 & 0,8 \\
\hline & La Cañada de La Cruz & 0,6 & $26-28$ & 0,6 & 0,8 \\
\hline & Benjamín Aráoz & 0,8 & $26-28$ & 0,6 & 0,8 \\
\hline & Tala Pozo I & 0,7 & $26-28$ & 0,6 & 0,8 \\
\hline & Tala Pozo II & 0,7 & $26-28$ & 0,6 & 0,8 \\
\hline & Gobernador Piedra Buena & 0,8 & $26-28$ & 0,6 & 0,8 \\
\hline & El Timbó Viejo & 0,7 & $22-26$ & 0,7 & 1,0 \\
\hline & El Sunchal & 0,7 & $22-26$ & 0,7 & 1,0 \\
\hline & Villa Padre Monti & 0,9 & $22-26$ & 0,7 & 1,0 \\
\hline & Río Nío & 0,6 & $22-26$ & 0,7 & 1,0 \\
\hline & Villa de Burruyacú & 0,4 & $26-28$ & 0,6 & 0,8 \\
\hline & Chilcas & 0,6 & $22-26$ & 0,7 & 1,0 \\
\hline & Requelme & 0,8 & $26-28$ & 0,6 & 0,8 \\
\hline & 7 de Abril & 0,7 & $26-28$ & 0,6 & 0,8 \\
\hline & Garmendia & 0,5 & $26-28$ & 0,6 & 0,8 \\
\hline & El Chañar & 0,7 & $22-26$ & 0,7 & 1,0 \\
\hline & Macomitas & 0,9 & $22-26$ & 0,7 & 1,0 \\
\hline & La Ramada & 1,1 & $26-28$ & 0,6 & 0,8 \\
\hline & El Cajón & 0,9 & $22-26$ & 0,7 & 1,0 \\
\hline & El Naranjo & 0,8 & $22-26$ & 0,7 & 1,0 \\
\hline & El Chañar Viejo & 0,5 & $26-28$ & 0,6 & 0,8 \\
\hline & Cañada de Alsogaray & 0,8 & $22-26$ & 0,7 & 1,0 \\
\hline Capital & San Miguel de Tucumán & 0,3 & $26-28$ & 0,6 & 0,8 \\
\hline \multirow{10}{*}{ Chicligasta } & Villa de Medinas & 0,3 & $26-28$ & 0,6 & 0,8 \\
\hline & San Ramón & 0,1 & $26-28$ & 0,6 & 0,8 \\
\hline & Concepción & 0,1 & $26-28$ & 0,6 & 0,8 \\
\hline & Arcadia & 0,2 & $26-28$ & 0,6 & 0,8 \\
\hline & Gastona Norte & 0,2 & $26-28$ & 0,6 & 0,8 \\
\hline & Belicha & 0,2 & $26-28$ & 0,6 & 0,8 \\
\hline & Gastona Sud & 0,2 & $26-28$ & 0,6 & 0,8 \\
\hline & El Molino & 0,1 & $22-26$ & 0,7 & 1,0 \\
\hline & La Trinidad & 0,4 & $26-28$ & 0,6 & 0,8 \\
\hline & Alpachiri & 0,3 & $22-26$ & 0,7 & 1,0 \\
\hline
\end{tabular}


Tabla 1. Continuación.

\begin{tabular}{|c|c|c|c|c|c|}
\hline \multirow[t]{2}{*}{ Departamento } & \multirow[t]{2}{*}{ Localidad } & \multirow{2}{*}{$\begin{array}{l}\text { Concentración de } \\
\text { fluoruros } \\
(\mathrm{mg} / \mathrm{l})\end{array}$} & \multirow{2}{*}{$\begin{array}{c}\text { Rango de } \\
\text { temperaturas } \\
\quad\left({ }^{\circ} \mathrm{C}\right)\end{array}$} & \multicolumn{2}{|c|}{ Límites de fluoruros } \\
\hline & & & & $\begin{array}{c}\text { Mínimo } \\
\text { (mg/l) }\end{array}$ & $\begin{array}{c}\text { Máximo } \\
(\mathrm{mg} / \mathrm{l})\end{array}$ \\
\hline \multirow{9}{*}{ La Cocha } & El Corralito & 0,5 & $22-26$ & 0,7 & 1,0 \\
\hline & Yanima & 0,5 & $22-26$ & 0,7 & 1,0 \\
\hline & Rumi Punco & 0,3 & $26-28$ & 0,6 & 0,8 \\
\hline & Pueblo Viejo & 0,7 & $26-28$ & 0,6 & 0,8 \\
\hline & Huasa Pampa & 0,9 & $22-26$ & 0,7 & 1,0 \\
\hline & La Cocha & 1,1 & $26-28$ & 0,6 & 0,8 \\
\hline & Los Pizarros & 1,0 & $22-26$ & 0,7 & 1,0 \\
\hline & Huasa Pampa Norte & 1,2 & $26-28$ & 0,6 & 0,8 \\
\hline & La Invernada & 0,4 & $26-28$ & 0,6 & 0,8 \\
\hline \multirow{11}{*}{ Tafí Viejo } & El Cadillal & 0,5 & $22-26$ & 0,7 & 1,0 \\
\hline & El Siambón & 0,1 & $22-26$ & 0,7 & 1,0 \\
\hline & Raco & 0,1 & $22-26$ & 0,7 & 1,0 \\
\hline & Granja Modelo & 0,5 & $26-28$ & 0,6 & 0,8 \\
\hline & Las Talitas & 0,5 & $26-28$ & 0,6 & 0,8 \\
\hline & El Colmenar & 0,5 & $26-28$ & 0,6 & 0,8 \\
\hline & Villa Mariano Moreno & 0,5 & $22-26$ & 0,7 & 1,0 \\
\hline & Los Nogales & 0,6 & $22-26$ & 0,7 & 1,0 \\
\hline & Tafí Viejo & 0,4 & $22-26$ & 0,7 & 1,0 \\
\hline & Los Pocitos & 0,3 & $22-26$ & 0,7 & 1,0 \\
\hline & Lomas de Tafí & 0,9 & $22-26$ & 0,7 & 1,0 \\
\hline \multirow{12}{*}{ Trancas } & San Pedro de Colalao & 0,3 & $22-26$ & 0,7 & 1,0 \\
\hline & Trancas & 0,2 & $22-26$ & 0,7 & 1,0 \\
\hline & Benjamín Paz & 0,2 & $22-26$ & 0,7 & 1,0 \\
\hline & Chuscha & 0,2 & $22-26$ & 0,7 & 1,0 \\
\hline & Choromoro & 0,4 & $22-26$ & 0,7 & 1,0 \\
\hline & Vipos & 0,2 & $22-26$ & 0,7 & 1,0 \\
\hline & Tapia & 0,2 & $22-26$ & 0,7 & 1,0 \\
\hline & Gonzalo & 0,4 & $22-26$ & 0,7 & 1,0 \\
\hline & Rodeo Grande & 0,5 & $22-26$ & 0,7 & 1,0 \\
\hline & Hualinchay & 0,1 & $22-26$ & 0,7 & 1,0 \\
\hline & Ticucho & 0,5 & $22-26$ & 0,7 & 1,0 \\
\hline & Las Arcas & 0,3 & $22-26$ & 0,7 & 1,0 \\
\hline \multirow{7}{*}{ Yerba Buena } & Villa Carmela & 0,2 & $22-26$ & 0,7 & 1,0 \\
\hline & San Javier & 0,3 & $22-27$ & 0,7 & 1,0 \\
\hline & Barrio Islas Malvinas & 0,2 & $22-26$ & 0,7 & 1,0 \\
\hline & La Rinconada & 0,4 & $22-26$ & 0,7 & 1,0 \\
\hline & Horco Molle & 0,1 & $22-26$ & 0,7 & 1,0 \\
\hline & El Corte & 0,2 & $22-27$ & 0,7 & 1,0 \\
\hline & Yerba Buena & 0,2 & $22-26$ & 0,7 & 1,0 \\
\hline
\end{tabular}


Tabla 1. Continuación.

\begin{tabular}{|c|c|c|c|c|c|}
\hline \multirow[t]{2}{*}{ Departamento } & \multirow[t]{2}{*}{ Localidad } & \multirow{2}{*}{$\begin{array}{l}\text { Concentración de } \\
\text { fluoruros } \\
(\mathrm{mg} / \mathrm{l})\end{array}$} & \multirow{2}{*}{$\begin{array}{c}\text { Rango de } \\
\text { temperaturas } \\
\left.\quad{ }^{\circ} \mathrm{C}\right)\end{array}$} & \multicolumn{2}{|c|}{ Límites de fluoruros } \\
\hline & & & & $\begin{array}{c}\text { Mínimo } \\
\text { (mg/l) }\end{array}$ & $\begin{array}{l}\text { Máximo } \\
\text { (mg/l) }\end{array}$ \\
\hline \multirow{10}{*}{ Cruz Alta } & Ranchillos & 0,4 & $26-28$ & 0,6 & 0,8 \\
\hline & Delfín Gallo & 0,8 & $26-28$ & 0,6 & 0,8 \\
\hline & Los Pereyra & 0,5 & $26-28$ & 0,6 & 0,8 \\
\hline & Banda del Río Salí & 0,6 & $26-29$ & 0,6 & 0,8 \\
\hline & Las Cejas & 0,5 & $26-28$ & 0,6 & 0,8 \\
\hline & Pacará & 0,6 & $26-28$ & 0,6 & 0,8 \\
\hline & Lastenia & 0,6 & $26-28$ & 0,6 & 0,8 \\
\hline & Colombres & 0,6 & $26-28$ & 0,6 & 0,8 \\
\hline & La Florida & 0,3 & $26-29$ & 0,6 & 0,8 \\
\hline & Alderete & 0,5 & $26-28$ & 0,6 & 0,8 \\
\hline \multirow{3}{*}{ Famaillá } & Nueva Baviera & 0,2 & $22-26$ & 0,7 & 1,0 \\
\hline & El Cruce & 0,2 & $22-26$ & 0,7 & 1,0 \\
\hline & Famaillá & 0,2 & $22-26$ & 0,7 & 1,0 \\
\hline \multirow{14}{*}{ Graneros } & Puesto Los Pérez & 0,6 & $26-28$ & 0,6 & 0,8 \\
\hline & Campo Bello & 0,5 & $26-28$ & 0,6 & 0,8 \\
\hline & Casas Viejas & 0,6 & $26-28$ & 0,6 & 0,8 \\
\hline & La Cañada & 0,7 & $26-28$ & 0,6 & 0,8 \\
\hline & Graneros & 0,8 & $26-28$ & 0,6 & 0,8 \\
\hline & Alto Puesto & 0,6 & $26-28$ & 0,6 & 0,8 \\
\hline & Lamadrid & 0,5 & $26-28$ & 0,6 & 0,8 \\
\hline & Las Animas & 0,6 & $26-28$ & 0,6 & 0,8 \\
\hline & Barrancas & 0,9 & $26-28$ & 0,6 & 0,8 \\
\hline & La Esperanza & 1,2 & $26-28$ & 0,6 & 0,8 \\
\hline & Árboles Grandes & 1,4 & $26-28$ & 0,6 & 0,8 \\
\hline & Paloma & 1,0 & $26-28$ & 0,6 & 0,8 \\
\hline & La Iguana & 1,7 & $26-28$ & 0,6 & 0,8 \\
\hline & Taco Ralo & 0,6 & $26-28$ & 0,6 & 0,8 \\
\hline \multirow{14}{*}{ Leales } & Las Encrucijadas & 0,4 & $26-28$ & 0,6 & 0,8 \\
\hline & Puesto Chico & 0,4 & $26-28$ & 0,6 & 0,8 \\
\hline & Los Herreras & 0,5 & $26-28$ & 0,6 & 0,8 \\
\hline & Los Romanos & 0,5 & $26-28$ & 0,6 & 0,8 \\
\hline & Los Gómez & 0,3 & $26-28$ & 0,6 & 0,8 \\
\hline & La Cañada & 0,4 & $26-28$ & 0,6 & 0,8 \\
\hline & Los Juárez & 0,4 & $26-28$ & 0,6 & 0,8 \\
\hline & Los Quemados & 0,3 & $26-28$ & 0,6 & 0,8 \\
\hline & Mancopa & 0,4 & $26-28$ & 0,6 & 0,8 \\
\hline & El Chilcal & 0,3 & $26-28$ & 0,6 & 0,8 \\
\hline & Cóndor Huasi & 0,3 & $26-28$ & 0,6 & 0,8 \\
\hline & Orán & 0,3 & $26-28$ & 0,6 & 0,8 \\
\hline & Viclos & 0,5 & $26-28$ & 0,6 & 0,8 \\
\hline & Campo Quimil & 0,8 & $26-28$ & 0,6 & 0,8 \\
\hline
\end{tabular}


Tabla 1. Continuación.

\begin{tabular}{|c|c|c|c|c|c|}
\hline \multirow[t]{2}{*}{ Departamento } & \multirow[t]{2}{*}{ Localidad } & \multirow{2}{*}{$\begin{array}{l}\text { Concentración de } \\
\text { fluoruros } \\
(\mathrm{mg} / \mathrm{l})\end{array}$} & \multirow{2}{*}{$\begin{array}{c}\text { Rango de } \\
\text { temperaturas } \\
\left({ }^{\circ} \mathrm{C}\right)\end{array}$} & \multicolumn{2}{|c|}{ Límites de fluoruros } \\
\hline & & & & $\begin{array}{c}\text { Mínimo } \\
\text { (mg/l) }\end{array}$ & $\begin{array}{c}\text { Máximo } \\
\text { (mg/l) }\end{array}$ \\
\hline \multirow{19}{*}{ Leales } & El Mollar & 0,6 & $26-28$ & 0,6 & 0,8 \\
\hline & Agua Dulce & 0,8 & $26-28$ & 0,6 & 0,8 \\
\hline & Agua Salada & 0,8 & $26-28$ & 0,6 & 0,8 \\
\hline & Carancho Pozo & 0,6 & $26-28$ & 0,6 & 0,8 \\
\hline & La Florida & 0,5 & $26-28$ & 0,6 & 0,8 \\
\hline & Los Puestos & 0,3 & $26-28$ & 0,6 & 0,8 \\
\hline & García Fernández & 0,4 & $26-28$ & 0,6 & 0,8 \\
\hline & Las Talas & 0,5 & $26-28$ & 0,6 & 0,8 \\
\hline & Bella Vista & 0,4 & $26-28$ & 0,6 & 0,8 \\
\hline & Río Colorado & 0,5 & $26-28$ & 0,6 & 0,8 \\
\hline & Esquina & 0,6 & $26-28$ & 0,6 & 0,8 \\
\hline & Quilmes-Pala Pala & 0,6 & $26-28$ & 0,6 & 0,8 \\
\hline & Ingenio Leales & 0,5 & $26-28$ & 0,6 & 0,8 \\
\hline & Villa Fiat & 0,5 & $26-28$ & 0,6 & 0,8 \\
\hline & Los Sueldos & 0,6 & $26-28$ & 0,6 & 0,8 \\
\hline & Santa Rosa de Leales & 0,4 & $26-28$ & 0,6 & 0,8 \\
\hline & Estación Aráoz & 0,2 & $26-28$ & 0,6 & 0,8 \\
\hline & San José de B. Vista & 0,2 & $26-28$ & 0,6 & 0,8 \\
\hline & Tacanas & 0,6 & $26-28$ & 0,6 & 0,8 \\
\hline \multirow{7}{*}{ Lules } & La Bolsa & 0,3 & $26-28$ & 0,6 & 0,8 \\
\hline & San Rafael & 0,3 & $22-26$ & 0,7 & 1,0 \\
\hline & San Isidro & 0,3 & $22-26$ & 0,7 & 1,0 \\
\hline & Malvinas & 0,2 & $22-26$ & 0,7 & 1,0 \\
\hline & Villa del Rosario & 0,3 & $22-26$ & 0,7 & 1,0 \\
\hline & San Pablo & 0,3 & $22-26$ & 0,7 & 1,0 \\
\hline & Ohuanta & 0,4 & $22-26$ & 0,7 & 1,0 \\
\hline \multirow{12}{*}{ Monteros } & Acheral & 0,2 & $26-28$ & 0,6 & 0,8 \\
\hline & Sargento Moya & 0,1 & $22-26$ & 0,7 & 1,0 \\
\hline & Capitán Cáceres & 0,3 & $22-26$ & 0,7 & 1,0 \\
\hline & El Churqui & 0,2 & $22-26$ & 0,7 & 1,0 \\
\hline & Yonopongo & 0,3 & $22-26$ & 0,7 & 1,0 \\
\hline & Los Costillas & 0,3 & $26-28$ & 0,6 & 0,8 \\
\hline & León Rouges & 0,3 & $26-28$ & 0,6 & 0,8 \\
\hline & Villa Quinteros & 0,2 & $26-28$ & 0,6 & 0,8 \\
\hline & Monteros & 0,2 & $26-28$ & 0,6 & 0,8 \\
\hline & El Cercado & 0,3 & $22-26$ & 0,7 & 1,0 \\
\hline & Soldado Maldonado & 0,3 & $22-26$ & 0,7 & 1,0 \\
\hline & Los Sosa & 0,3 & $22-26$ & 0,7 & 1,0 \\
\hline
\end{tabular}


Tabla 1. Continuación.

\begin{tabular}{|c|c|c|c|c|c|}
\hline \multirow[t]{2}{*}{ Departamento } & \multirow[t]{2}{*}{ Localidad } & \multirow{2}{*}{$\begin{array}{l}\text { Concentración de } \\
\text { fluoruros } \\
(\mathrm{mg} / \mathrm{l})\end{array}$} & \multirow{2}{*}{$\begin{array}{c}\text { Rango de } \\
\text { temperaturas } \\
\left.\quad{ }^{\circ} \mathrm{C}\right)\end{array}$} & \multicolumn{2}{|c|}{ Límites de fluoruros } \\
\hline & & & & $\begin{array}{c}\text { Mínimo } \\
\text { (mg/l) }\end{array}$ & $\begin{array}{c}\text { Máximo } \\
\text { (mg/l) }\end{array}$ \\
\hline \multirow{7}{*}{ Río Chico } & Villa Hileret & 0,4 & $26-28$ & 0,6 & 0,8 \\
\hline & Santa Ana & 0,3 & $22-26$ & 0,7 & 1,0 \\
\hline & Colonia 6 & 1,1 & $22-26$ & 0,7 & 1,0 \\
\hline & Monte Bello & 0,4 & $22-26$ & 0,7 & 1,0 \\
\hline & Los Lunas & 0,8 & $22-26$ & 0,7 & 1,0 \\
\hline & Aguilares & 0,3 & $26-28$ & 0,6 & 0,8 \\
\hline & Los Sarmientos & 0,4 & $22-26$ & 0,7 & 1,0 \\
\hline \multirow{12}{*}{ Simoca } & Atahona & 0,2 & $26-28$ & 0,6 & 0,8 \\
\hline & Villa Chicligasta & 0,7 & $26-28$ & 0,6 & 0,8 \\
\hline & Monteagudo & 0,2 & $26-28$ & 0,6 & 0,8 \\
\hline & Niogasta & 0,3 & $26-28$ & 0,6 & 0,8 \\
\hline & Ciudacita & 0,2 & $26-28$ & 0,6 & 0,8 \\
\hline & Los Agudos & 0,4 & $26-28$ & 0,6 & 0,8 \\
\hline & Simoca & 0,1 & $26-28$ & 0,6 & 0,8 \\
\hline & Güemes & 0,2 & $26-28$ & 0,6 & 0,8 \\
\hline & San Pedro Mártir & 0,2 & $26-28$ & 0,6 & 0,8 \\
\hline & La Tuna & 0,2 & $26-28$ & 0,6 & 0,8 \\
\hline & Manuela Pedraza & 0,3 & $26-28$ & 0,6 & 0,8 \\
\hline & Buena Vista & 0,2 & $26-28$ & 0,6 & 0,8 \\
\hline \multirow{14}{*}{ Tafí del Valle } & Ampimpa & 0,3 & $22-26$ & 0,7 & 1,0 \\
\hline & Los Zazos & 0,4 & $22-26$ & 0,7 & 1,0 \\
\hline & El Pichao & 0,1 & $22-26$ & 0,7 & 1,0 \\
\hline & Colalao del Valle & 0,9 & $22-26$ & 0,7 & 1,0 \\
\hline & El Bañado & 1,8 & $22-26$ & 0,7 & 1,0 \\
\hline & Quilmes & 0,6 & $22-26$ & 0,7 & 1,0 \\
\hline & Amaicha & 0,9 & $22-26$ & 0,7 & 1,0 \\
\hline & Tafí del Valle & 0,2 & 19 & 0,7 & 1,2 \\
\hline & La Ovejería & 0,1 & 19 & 0,7 & 1,2 \\
\hline & El Rodeo & 0,1 & 19 & 0,7 & 1,2 \\
\hline & Las Carreras & 0,1 & 19 & 0,7 & 1,2 \\
\hline & El Mollar & 0,2 & 19 & 0,7 & 1,2 \\
\hline & La Costa II & 0,2 & 19 & 0,7 & 1,2 \\
\hline & La Costa I & 0,2 & 19 & 0,7 & 1,2 \\
\hline
\end{tabular}

Fuente: Elaboración propia.

794.327 habitantes ${ }^{(23)}$, siendo el quinto conglomerado urbano de la Argentina, con una densidad de $6.967 \mathrm{hab} / \mathrm{km}^{2}$. La zona geográfica Oeste I comprende a las localidades próximas a la ciudad cabecera del departamento de Tafí del Valle con registros de temperaturas máximas medias anuales cercanas a los $19^{\circ} \mathrm{C}$. 


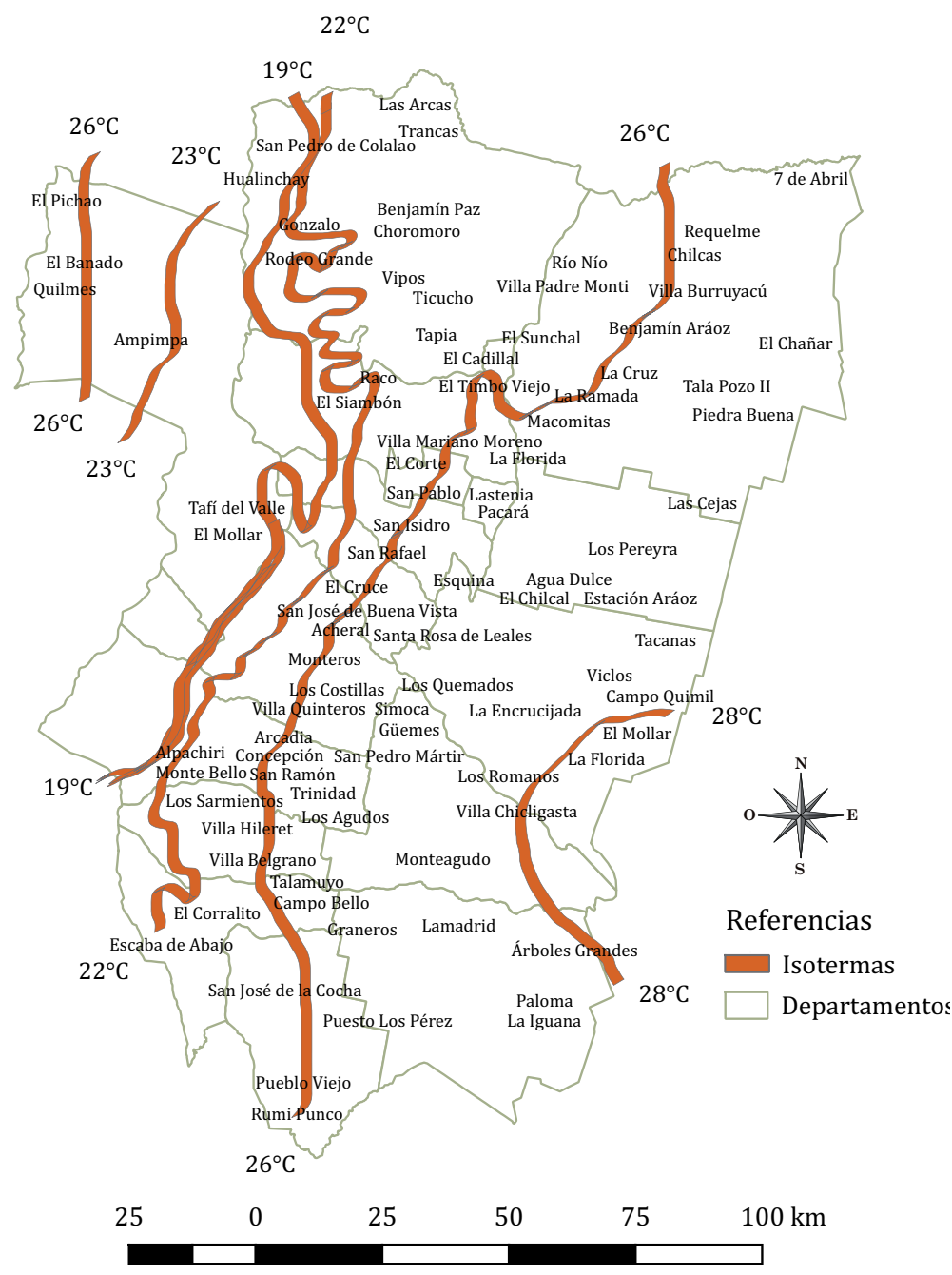

Figura 2. Isotermas de temperaturas máximas medias anuales y localidades georeferenciadas relevadas. Provincia de Tucumán, Argentina, 2012.

Fuente: Elaboración propia con base en mapa de isotermas máximas medias anuales de Torres Bruchmann ${ }^{(27,28)}$ y geotato del Instituto Geográfico Nacional ${ }^{(30)}$.

Tabla 2. Zonas estudiadas según rangos de temperaturas máximas medias anuales y límites recomendados por el Código Alimentario Argentino. Provincia de Tucumán, Argentina, 2008-2012.

$\begin{array}{lcccc}\text { Zonas } & \begin{array}{c}\text { Rango de isotermas } \\ \text { de temperatura } \\ \text { máxima media anual }\end{array} & \begin{array}{c}\text { Rango de } \\ \text { temperatura } \\ \text { máxima media anual }{ }^{1}\end{array} & \begin{array}{c}\text { Límites de fluoruros }{ }^{1} \\ \text { Inferior } \\ (\mathrm{mg} / \mathrm{C})\end{array} & \begin{array}{c}\text { Superior } \\ (\mathrm{mg} / \mathrm{l})\end{array} \\ \text { Este } & 26-28 & \left({ }^{\circ} \mathrm{C}\right) & 0,6 & 0,8 \\ \text { Centro } & 26-22 & 26,3-32,6 & 0,7 & 1,0 \\ \text { Oeste I } & 19 & 21,5-26,2 & 0,7 & 1,2 \\ \text { Oeste II } & 26-23 & 17,7-21,4 & 0,7 & 1,0\end{array}$

Fuente: Elaboración propia.

${ }^{1}$ Límites recomendados por el Código Alimentario Argentino. 


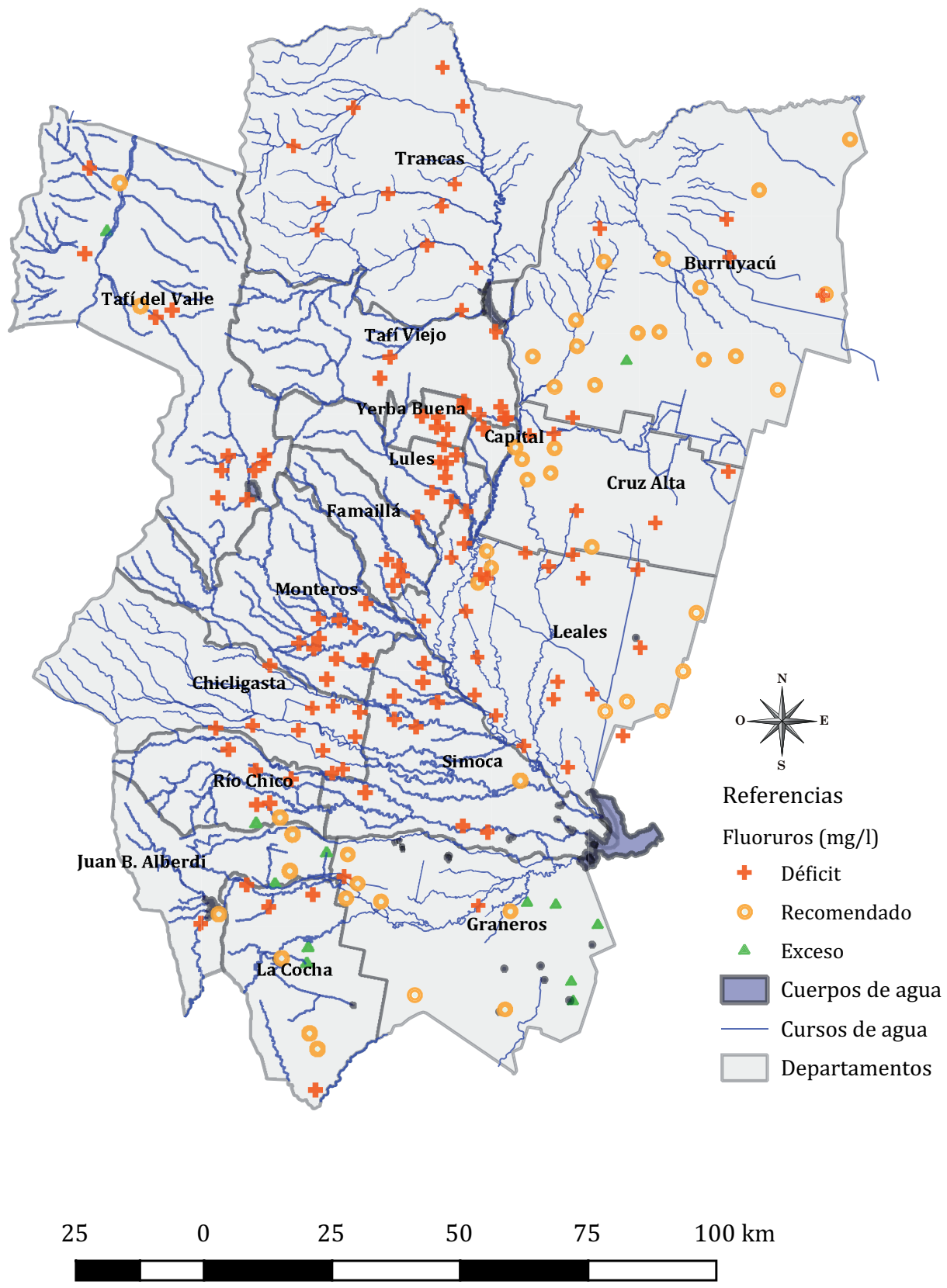

Figura 3. Distribución geográfica de cursos de agua y concentraciones de fluoruros clasificadas en tres tipos: déficit, recomendado y exceso. Provincia de Tucumán, Argentina, 2008-2012.

Fuente: Elaboración propia con base en geodato del Instituto Geográfico Nacional ${ }^{(30)}$.

Se identificaron los requerimientos del contenido de fluoruros de las localidades estudiadas, de acuerdo a las temperaturas máximas medias anuales del aire (Tabla 2), según lo establecido por el Código Alimentario Argentino(24).
La Figura 3 muestra la distribución geográfica de cursos de agua y concentraciones de fluoruros clasificadas en tres tipos: déficit, recomendado y exceso. En la Figura 4 se representa la distribución de fluoruros para San Miguel de Tucumán. 


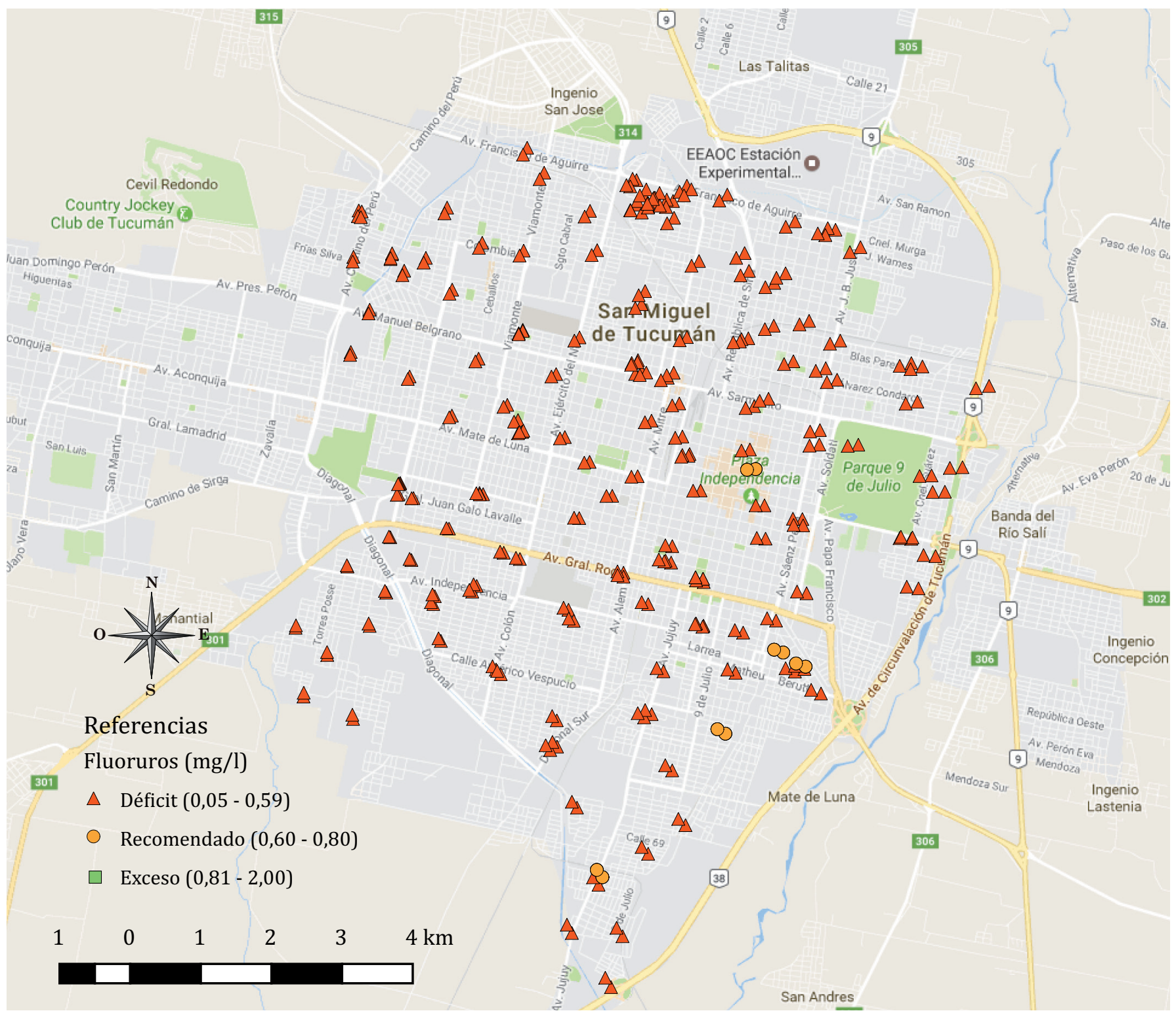

Figura 4. Distribución geográfica de concentraciones de fluoruros en agua de red de San Miguel de Tucumán clasificada en tres tipos: déficit, recomendado y exceso. Provincia de Tucumán, Argentina, 2008-2012.

Fuente: Elaboración propia con base en geodato del Instituto Geográfico Nacional ${ }^{(30)}$.

La Figura 5 muestra la distribución de frecuencias de concentraciones de fluoruros en agua de red en San Miguel de Tucumán. Los resultados promedios fueron agrupados en rangos de concentraciones, con un incremento de concentración de $0,1 \mathrm{mg} / \mathrm{l}$ para cada grupo relacionando.

La población de las localidades estudiadas alcanzó a 1.250 .700 habitantes $(86,36 \%$ del total de habitantes de la provincia), de los cuales 1.170. 000 consumen agua con déficit de fluoruros y 59.000 están expuestos a un exceso de fluoruros. Solo 15.000 habitantes ( $1 \%$ disponen de agua que contiene fluoruros en concentraciones recomendadas.

El contenido de fluoruros en el agua de consumo fue clasificada en tres tipos: déficit, recomendado y exceso (Figura 3). Los departamentos de Tafí del Valle, Graneros, La Cocha, Burruyacu, Cruz Alta, Leales y Alberdi 
presentaron variaciones espaciales en las concentraciones recomendadas de fluoruros en el agua. Los restantes departamentos, presentaron, en general, una distribución con déficit de fluoruros en el agua de bebida.

La Figura 6 muestra la densidad de Kernel para la concentración de fluoruros en el agua de red en la provincia de Tucumán. El complemento "mapa de calor" de QGis 2.16 utiliza la estimación de la densidad de Kernel para crear un raster de densidad a partir de una capa vectorial de puntos de entrada. La densidad se calcula sobre la base del número de puntos en cada localización de forma que un número más grande de puntos vectoriales agrupados dan resultados mayores (expresada en unidades del mapa). Esto determina la forma del Kernel que controla el rango en el cual la influencia de un punto decrece a medida que la distancia desde el punto aumenta. Así mismo, el ancho de banda especifica la distancia alrededor de un punto en el que sentirá la influencia de los puntos vecinos permitió estimar la concentración de fluoruros en zonas no relevadas, a partir de sitios muestreados, teniendo en cuenta las temperaturas máximas medias anuales de la zona (Figura 6).

\section{DISCUSIÓN}

\section{Distribución espacial de las concentraciones de fluoruros}

El presente trabajo constituye el primer relevamiento de la distribución geográfica de fluoruros en el agua de consumo de la provincia de Tucumán. Las muestras fueron razonablemente representativas y se podría asumir que la distribución geográfica de fluoruros representa la real situación de la concentración de fluoruros en el agua de la provincia.

En este estudio el contenido de fluoruros en el agua de consumo y sus variaciones espaciales fueron investigadas usando las técnicas del Sistema de Información Geográfica (SIG) que permiten analizar la información geográfica relevada a fin de resolver problemas complejos de planificación y gestión.

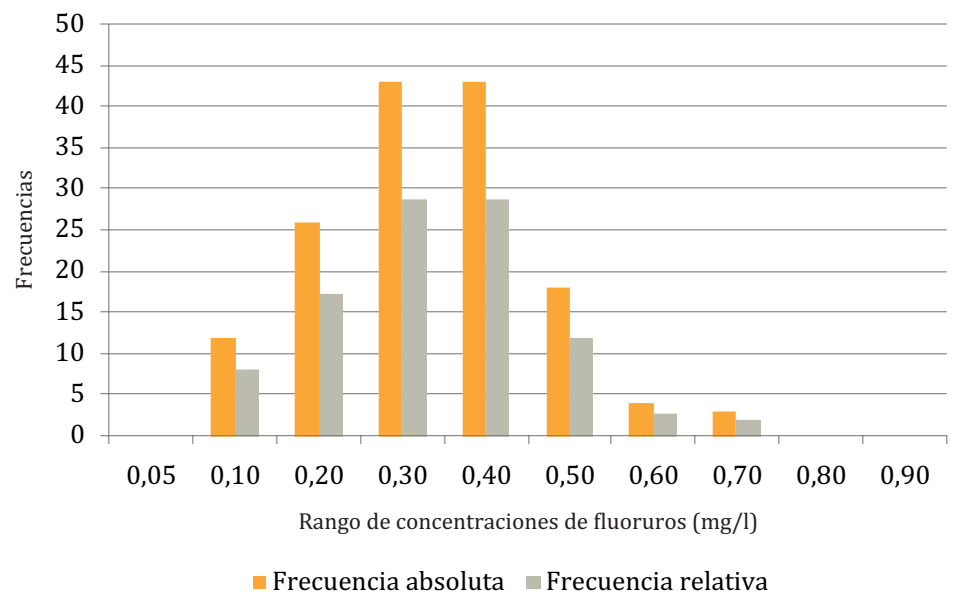

Figura 5. Distribución de frecuencias de concentraciones de fluoruros en el agua de red (149 muestras). San Miguel de Tucumán, provincia de Tucumán, Argentina, 2008-2012. 


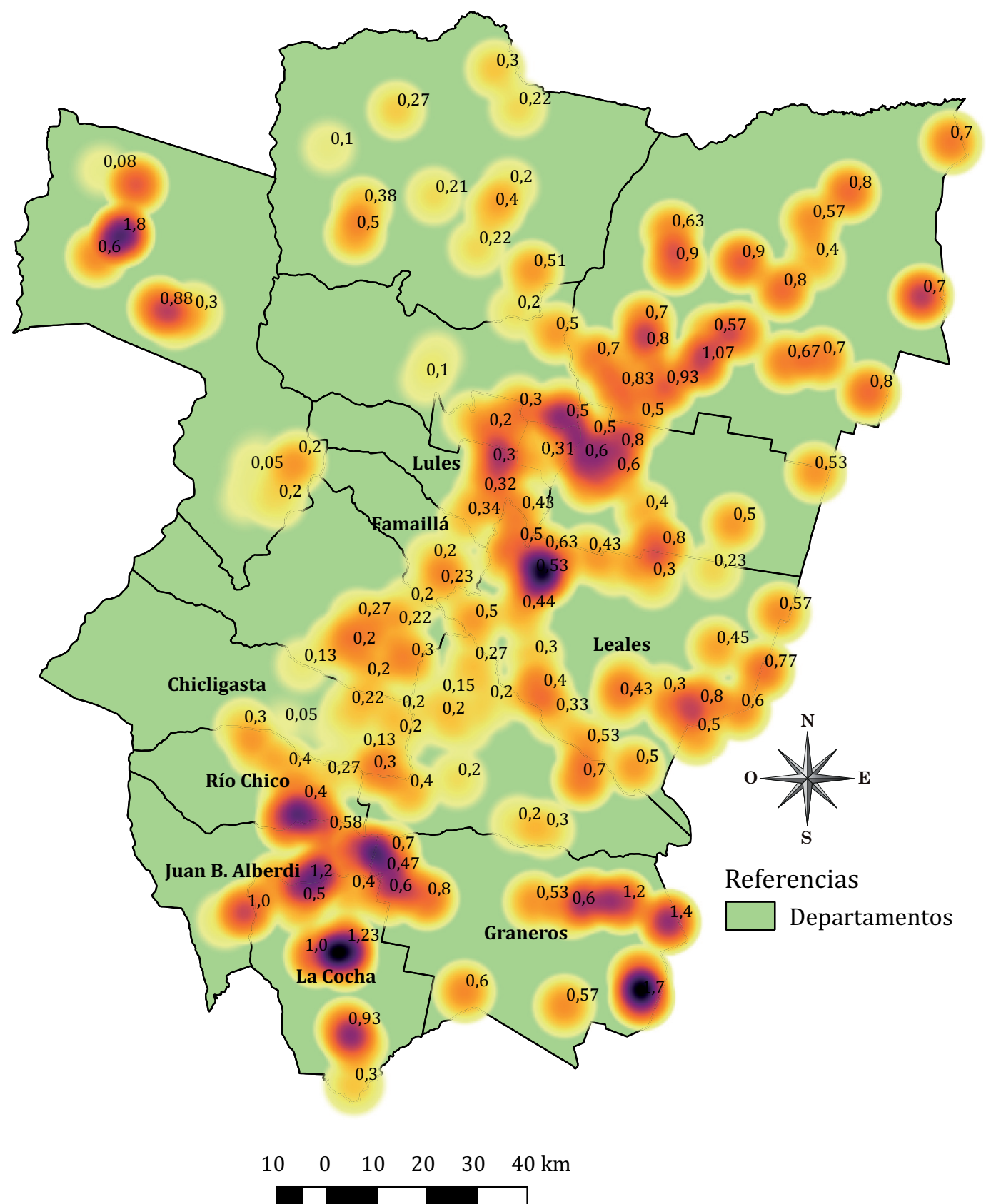

Figura 6. Estimación de la densidad de Kernel para la concentración de fluoruros en el agua de red. Provincia de Tucumán, Argentina, 2008-2012.

Fuente: Elaboración propia con base en geodato del Instituto Geográfico Nacional(30).

La distribución de la concentración de fluoruros en el agua de consumo es heterogénea (Figura 1), coincidentes con relevamientos realizados en otros países ${ }^{(12)}$.
La diferenciación de zonas de temperaturas máximas medias anuales propuestas para la provincia de Tucumán (Figura 2 y Tabla 2), permitió la evaluación del contenido 
de fluoruros en el agua de consumo (Tabla 1), acorde a las recomendaciones del Código Alimentario Argentino ${ }^{(24)}$.

La red hidrológica de Tucumán es una de las más importantes de la región. Las cuencas de alimentación descienden de las cumbres Calchaquíes y del Cordón del Aconquija y sus cursos de aguas lixivian las rocas y el suelo, que influyen según su naturaleza geológica en la concentración de fluoruros en el agua, en concordancia con lo informado por Cuellar Luna y García Melián ${ }^{(13)}$. En la Figura 3 se observa a simple vista, para los departamentos de Simoca, Chicligasta, Monteros, Famaillá, Lules y Trancas, una relación inversa entre las concentraciones de fluoruros y la densidad de la red hidrológica.

Por otro lado, aquellas localidades cuyas fuentes de abastecimientos eran pozos, surgentes, semisurgentes y profundos presentaron exceso de fluoruros en el agua de bebida, de forma coincidente con TekleHaimanot et al. ${ }^{(12)}$, quienes informaron elevados contenidos de fluoruros en el agua provenientes de pozos profundos.

En San Miguel de Tucumán se encontró, una acumulación de frecuencias superiores al $50 \%$, entre las concentraciones de $0,30 \mathrm{mg} / \mathrm{l}$ y $0,40 \mathrm{mg} / \mathrm{l}$, con un valor promedio de 0,32 $\mathrm{mg} / \mathrm{l}$ y una mediana de $0,30 \mathrm{mg} / \mathrm{l}$ (Figura 5). En algunas localidades montañosas del departamento Tafí del Valle, los niveles de fluoruros mostraron mayor déficit con respecto a los niveles óptimos recomendados con relación a otros departamentos estudiados.

\section{Adecuado manejo del flúor}

La caries dental es un problema de salud pública mundial con una alta prevalencia en Argentina $^{(3)}$ y asociada a la exposición a los fluoruros, por lo que la información del presente trabajo se torna indispensable para el manejo adecuado del flúor en el agua de bebida por las autoridades sanitarias, teniendo en cuenta los antecedentes con intervenciones positivas de reducción de los índices de caries por fluoración del agua, la leche o la sal y el uso de pastas fluoradas ${ }^{(13,15,31)}$. Del mismo modo, la información es útil para evitar la fluoración en aquellas localidades con concentraciones recomendadas y en exceso de fluoruros.

La prevención es una meta básica en la medicina y la odontología para evitar el inicio de la enfermedad y su desarrollo posterior ${ }^{(32)}$. Una forma de prevención de la caries dental requiere de programas centrados en el manejo de la fluoración del agua de abastecimiento, de la sal para consumo humano y el uso extendido de cremas dentífricas fluoradas ${ }^{(33)}$. Estas medidas han probado tener efectos beneficiosos para prevenir la caries en varios países de América y Europa ${ }^{(34)}$.

La fluoración del agua es una forma segura, eficaz y barata de evitar la caries dental que beneficia a las personas de todos los grupos etarios y niveles socioeconómicos. Además, es la forma de prevenir la caries dental con la mejor relación costoefectividad $^{(1,10,15)}$. La fluoración del agua es una de las pocas medidas de salud pública que proporcionan un verdadero ahorro de costos. Incluso en las condiciones más desfavorables, el costo medio de la fluoración del agua por superficie cariada evitada es muy inferior al costo de la restauración dental ${ }^{(34)}$. El uso de dentífricos fluorados, con la concentración adecuada de fluoruros, es una forma de reducir la prevalencia de la caries dental con una buena relación costo-efectividad ${ }^{(34)}$.

Las implicancias del presente trabajo involucran la optimización de medidas preventivas de cada zona de la provincia, identificando estrategias eficaces para promover la adopción de las recomendaciones actuales sobre el uso de fluoruros. Dichas estrategias deben estar dirigidas tanto a los adultos como a los niños, a sus padres y a los profesionales sanitarios.

A partir de la información obtenida en este estudio, sobre los resultados del contenido de fluoruros en el agua de red y los límites recomendados por el Código Alimentario Argentino, es posible tomar medidas para mejorar la salud dental de la población en general por medio de programas preventivos para la promoción de la salud ${ }^{(34)}$. 


\section{CONCLUSIONES}

Esta investigación, realizada por primera vez en la provincia, permitió la elaboración de mapas de distribución geográfica de la concentración de fluoruros en el agua de bebida, utilizando las técnicas de los sistemas de información geográfica. Por medio de esta metodología se relacionó espacialmente la concentración de fluoruros de 1.210 muestras de agua de consumo, con las características hidrológicas, geográficas y socioeconómicas de Tucumán.

Se relevó la concentración de fluoruros en el agua de consumo, de 190 localidades de los 17 departamentos de la provincia, durante el periodo 2008-2012. Los resultados analíticos obtenidos se evaluaron a partir de la diferenciación en la provincia, de zonas con registros de temperatura del aire diferentes. Para ello, se identificaron cuatro zonas en la provincia con rangos térmicos diferentes, lo cual permitió distinguir en las localidades relevadas, los rangos de temperaturas máximas medias anuales del aire. Se identificaron los requerimientos del contenido de fluoruros en el agua de consumo, de las localidades estudiadas, según las exigencias del Código Alimentario Argentino.

Se podría considerar, en general, a la provincia de Tucumán como flúor carencial, ya que se encontró que el $94 \%$ de la población estudiada consumía agua con concentraciones de fluoruros inferiores a los límites recomendados, que el 5\% estuvo expuesta a concentraciones superiores al límite permitido, y solo el $1 \%$ consumía agua con las concentraciones de fluoruros recomendadas.

Los mapas elaborados de Tucumán muestran una distribución heterogénea de los fluoruros en el agua de consumo y se observa, en general, una relación inversa entre la concentración de fluoruros y la densidad de la red hidrológica de la provincia. En San Miguel de Tucumán se encontró un valor promedio de concentración de fluoruros de 0,32 mg/l y la distribución espacial de los sitios de muestreos no presentaron relación directa con los indicadores socioeconómicos estudiados.

Las técnicas de análisis espaciales exploratorios empleadas permitieron estimar las concentraciones de fluoruros en localidades no relevadas. Es destacable el déficit de contenidos de fluoruros en el agua de consumo de algunos departamentos de la provincia, especialmente, en los grandes conglomerados urbanos. Asimismo, se distinguieron localidades con exceso de concentración de fluoruros en el agua.

Esta información es indispensable para encarar planes y medidas sanitarias en beneficio de la salud de la población, ya que el adecuado manejo del flúor permitirá mejorar las prácticas, reducir costos y encarar políticas sanitarias. A partir de los resultados obtenidos en el presente trabajo, se prevé dar continuidad a esta investigación, relacionando otros factores de importancia sanitaria, mediante las técnicas del SIG, en beneficio de la salud pública.

\section{AGRADECIMIENTOS}

Para el desarrollo de este trabajo se contó con una Beca "Ramón Carrillo-Arturo Oñativia" 2012 para estudios individuales de investigación en salud pública, categoría iniciación, Comisión Nacional Salud Investiga, Ministerio de Salud de la Nación.

\section{REFERENCIAS BIBLIOGRÁFICAS}

1. The World Oral Health Report 2003: continuous improvement of oral health in the 21st century the approach of the WHO Global Oral Health Programme. Geneva: World Health Organization; 2003.
2. Montero Canseco D, López Morales P, Castrejón Pérez RC. Prevalencia de caries de la infancia temprana y nivel socioeconómico familiar. Revista Odontológica Mexicana. 2011;15(2):96-102.

3. Sociedad Argentina de Pediatría, Universidad de Buenos Aires. Flúor y prevención de caries en los niños. Buenos Aires: Comité Nacional de Pediatría Ambulatoria; 2006.

4. Núñez DP, García Bacallao L. Bioquímica de la caries dental. Revista Habanera de Ciencias Médicas [Internet]. 2010;9 [citado 10 may 2016]. Disponible en: http://tinyurl.com/zyrkmn8. 
5. Organización Mundial de la Salud. Etiología y prevención de la caries dental (Informe Técnico N 494). Ginebra: OMS; 1972.

6. Lynch RJ, Navada R, Walia R. Low-levels of fluoride in plaque and saliva and their effects on the demineralisation and remineralisation of enamel; role of fluoride toothpastes. International Dental Journal. 2004;54(Suppl. 1):304-309.

7. Newby EE, Martinez-Mier EA, Zero DT, Kelly SA, Fleming N, North M, Bosma ML. A randomised clinical study to evaluate the effect of brushing duration on fluoride levels in dental biofilm fluid and saliva in children aged $4-5$ years. International Dental Journal. 2013;63(Suppl. 2):39-47.

8. Sosa-Rosales M. Evolución de la fluoruración como medida para prevenir la caries dental. Revista Cubana de Salud Pública. 2003;29(3):268-274.

9. Mckay FS. The establishment of a definite relationship between enamel that is defective in its structure, as mottled enamel, and the liability to decay. Dental Cosmos. 1929;71:747-755.

10. Zaror C, Vallejos C, Corsini G, De La Puente C, Velásquez M, Tessada-Sepúlveda R, Del ValleAranda C, Vega-Rodríguez G. Revisión sistemática sobre los efectos adversos de la fluoración del agua. International Journal of Odontostomatology. 2015;9(1):165-171.

11. Buzai GD. Análisis espacial con sistemas de información geográfica: sus cinco conceptos fundamentales. En: Geografía y Sistemas de Información Geográfica: Aspectos conceptuales y aplicaciones. Buenos Aires: Universidad Nacional de Luján, GESIG; 2010. p. 163-195.

12. Tekle-Haimanot $\mathrm{R}$, Melaku Z, Kloos H, Reimann C, Fantaye W, Zerihun L, Bjorvatn K. The geographic distribution of fluoride in surface and groundwater in Ethiopia with an emphasis on the Rift Valley. The Science of the Total Environment. 2006;367(1):182-190.

13. Cuellar-Luna L, García-Melián M. El fluoruro en aguas de consumo y su asociación con variables geológicas y geográficas de Cuba. Revista Panamericana de Salud Pública. 2003;14(5):341-349.

14. Mitchell C, Craig C, Wilson D. National Health and medical Research Council. A systematic review of the efficacy and safety of fluoridation, Part A: Review methodology and results. Sidney: Australian Government, National Health and Medical Research Council; 2007.

15. Muñoz Millán P, Espinoza Espinoza G, Nuñez G, Sanhueza Campos A. Disponibilidad de flúor en saliva y biofilms en escolares expuestos a leche o agua fluorurada. International Journal of Odontostomatology. 2015;9(3):393-398.

16. Carmo CDS, Coelho Alves MC, Cavalcante PR, Costa Ribeiro CC. Avaliação da fluoretação da água do sistema de abastecimento público na Ilha de São Luís, Maranhão, Brasil. Ciência \& Saúde Coletiva. 2010;15(1):1835-1840.

17. Armfield JM. Community effectiveness of public water fluoridation in reducing children's dental disease. Public Health Reports. 2010;125(5):655-664.

18. Davraz A, Sener E, Sener S. Temporal variations of fluoride concentration in Isparta public water system and health impact assessment (SW-Turkey). Environmental Geology. 2008;56(1):159-170.

19. Avila Carreras N, Farias SS, Bianco G, Bovi Mitre MG. Determinación de fluoruro en aguas de Rinconadillas (Provincia de Jujuy). Acta Toxicológica Argentina. 2008;16(1):14-20.

20. Osicka RM, Agulló NS, Herrera Ahuad CE, Giménez MC. Evaluación de las concentraciones de fluoruro y arsénico en las aguas subterráneas del Domo Central de la provincia del Chaco [Internet]. Corrientes: Facultad de Agroindustrias, Universidad Nacional del Nordeste; 2002 [citado 9 jun 2015]. Disponible en: http://tinyurl.com/ zzrc8me.

21. Juárez M, Luján J. Contenido de fluoruros en el agua y alimentos en la provincia de Tucumán: Propuesta para la salud dental. Tucumán: Dirección General de Salud Ambiental, Sistema Provincial de Salud; 1986.

22. U.S. Department of Health, Education and Welfare. Public Health Service Drinking Water Standards. Washington DC: Public Health Service; 1962.

23. Organización Mundial de la Salud. Guías para la calidad del agua potable (Vol. I, II, III). Washington DC: OMS; 1998.

24. Administración Nacional de Medicamentos, Alimentos y Tecnología Médica. Capítulo XII: Bebidas hídricas, agua y agua gasificada. En: Código Alimentario Argentino. Buenos Aires: ANMAT; 2007.

25. Instituto Nacional de Estadística y Censos. Censo 2010 [Internet]. Buenos Aires: INDEC; 2010 [citado 9 jun 2015]. Disponible en: http:// tinyurl.com/zqftbf5

26. APHA, AWWA, WPCF. Métodos normalizados para el análisis de aguas potables y residuales. 17a ed. Madrid: Ediciones Diaz de Santos; 1992. 
27. Torres Bruchmann E. Atlas agroclimático y bioclimático de Tucumán (1a Parte). San Miguel de Tucumán: Universidad Nacional de Tucumán; 1976.

28. Torres Bruchmann E. Atlas agroclimático y bioclimático de Tucumán (2a Parte). San Miguel de Tucumán: Universidad Nacional de Tucumán; 1977.

29. Minetti JL, Laboratorio Climático Sudamericano. El clima del noroeste argentino [CD-Rom]. Tucumán: Editorial Magna; 2012.

30. Instituto Geográfico Nacional. Base de datos Geográfica [Internet]. Buenos Aires: Ministerio de Defensa [citado 10 jun 2015]. Disponible en: http://www.ign.gob.ar/sig.

31. Mattos Vela MA, Melgar Hermoza RA. Riesgo de caries dental. Revista Estomatológica Herediana. 2004;14(1-2):101-106.
32. Centers for Disease Control and Prevention. Recommendations for using fluoride to prevent and control dental caries in the United States. Mortality and Morbidity Weekly Reports. 2001;50(RR14): $1-42$

33. Bordoni N, Bellagamba $H$, Doño R, Piovano S, Marcantoni M, Squasasi A. Efecto del autocepillado con fluorfosfato de sodio acidulado $\mathrm{pH}$ 5,6 sobre la caries dental en niños. Boletín de la Asociación Argentina de Odontología para Niños. 1999;28(1):14-18.

34. Organización Mundial de la Salud, Organización Panamericana de la Salud. Salud en las Américas 2007 (Publicación Científica y Técnica $N^{\circ}$ 622). Washington DC: OPS; 2007.

\section{FORMA DE CITAR}

Durán RA, Durán EL, Ojeda GJ, Castellanos WA. Distribución geográfica de fluoruros en el agua de red de abastecimiento público en la provincia de Tucumán, Argentina. Salud Colectiva. 2017;13(1):105-122. doi: 10.18294/ sc. 2017.1033

Recibido: 22 de junio de 2016 | Versión final: 27 de enero de 2017 | Aprobado: 6 de febrero de 2017

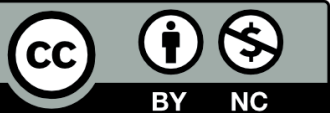

Este obra está bajo una licencia de Creative Commons Reconocimiento-NoComercial 4.0 Internacional. Reconocimiento - Permite copiar, distribuir y comunicar públicamente la obra. A cambio, se debe reconocer y citar al autor original. No Comercial - Esta obra no puede se utilizada con finalidades comerciales, a menos que se obtenga el permiso.

http://dx.doi.org/10.18294/sc.2017.1033 